\title{
Pengaruh Perbedaan Jarak Tanam terhadap Pertumbuhan Tiga Varietas Kedelai (Baluran, Bromo, dan Galunggung)
}

\author{
The Effect of the Planting Distance Differences on the Growth of Three Soybean \\ Varieties (Baluran, Bromo, and Galunggung)
}

\section{Djukri}

Jurusan Pendidikan Biologi, FMIPA UNY, Karangmalang, Yogyakarta

\begin{abstract}
The objective of the research was to investigate the effect of sunlight radiation distribution in canopy on soybean plants biomass at different planting distances. This research was done experimentally using the Block Design. The independent variables were the soybean varieties and planting distance. The varieties used were Baluran, Bromo, and Galunggung and the planting distance used was $15 \times 15 \mathrm{~cm}^{2}$ and $25 \times 25 \mathrm{~cm}^{2}$ as blocks with 10 replications. The dependent variables were sunlight intensity and the plants biomass. The result of the research indicated that after 40 planting days, the sunlight intensity in the canopy, at soybean varieties factors was significant $(p<0.05)$, and the planting distance was significant too. The plant biomass indicated that varieties factors had a significant effect $(p<0.05)$, but the planting distance factors were not significant $(\mathbf{p}>\mathbf{0 . 0 5})$.
\end{abstract}

Key words : sunlight distribution, planting distance, light intensity, and biomass

Diterima : 29 Maret 2005, disetujui : 28 Juli 2005

\section{Pendahuluan}

Sebaran cahaya pada kanopi tanaman merupakan faktor penting yang mempengaruhi efisiensi penggunaan cahaya matahari oleh tanaman. Salah satu faktor yang mempengaruhi sebaran cahaya dalam kanopi adalah struktur kanopi. Sebaran cahaya pada kanopi berdaun tegak (erectophil) lebih baik dibandingkan dengan kanopi yang berdaun horizontal. Karakteristik distribusi cahaya pada kanopi suatu tanaman ditunjukkan oleh besaran koefisien pemadaman cahaya (Newton and Blackman, 1969).

Tanaman kedelai termasuk tanaman C3 yang mempunyai laju fotorespirasi tinggi, tetapi fotosintesis neto yang dihasilkan pada umumnya lebih rendah dibanding tanaman C4 (Taiz dan Zeiger, 1991). Tanaman kedelai tidak efisien dalam penggunaan air. Pertumbuhan tanaman tidak lepas dari pemanfaatan energi radiasi surya, unsur hara dan air.
Jarak tanam yang berbeda kemungkinan dapat mempengaruhi efisiensi penangkapan energi radiasi untuk pertumbuhan tanaman. Pada jarak tanam yang rapat transmisi radiasi surya ke permukaan tanah lebih kecil dibanding dengan jarak tanam yang lebih longgar. Menurut Janick (1963), dengan pengaturan jarak tanam, hasil suatu tanaman dapat menjadi lebih optimal. Kebiasaan petani menanam tanaman pangan dengan jarak tanam yang selalu tetap untuk suatu daerah dengan iklim yang berbeda perlu mendapat perhatian, karena belum tentu mendapat hasil yang optimal.

Pada jenis-jenis tanaman tinggi proses fotosintesis memerlukan pigmen terutama klorofil untuk mengabsorbsi energi surya. Makin rendah intensitas radiasi Photosynthetic Active Radiation (PAR) yang digunakan, akan makin tinggi efisiensinya, karena semua energi akan digunakan. Menurut Monteith (1977), efisiensi penggunaan energi radiasi surya 
ditentukan oleh faktor-faktor : kejernihan atmosfer bumi (keawanan dan kandungan aorosol atmosfer), fraksi radiasi yang diintersepsi tajuk (indeks luas daun dan susunan daun), laju difusi karbon dioksida dari atmosfer ke permukaan pusat unit fotosintetik dalam sel (konsentrasi karbon dioksida), dan fraksi asimilat yang digunakan untuk respirasi.

Distribusi cahaya di dalam tajuk tanaman merupakan elemen penting yang akan mempengaruhi efisiensi konversi radiasi ke dalam bobot kering tanaman. Muchow et al., (1982) menyatakan bahwa efisiensi akan menjadi rendah apabila jumlah intensitas radiasi per satuan luas daun tinggi, dan sebaliknya efisiensi akan meningkat apabila cahaya didistribusikan ke dalam beberapa unit luas daun dengan intensitas rendah. Karakteristik distribusi cahaya di dalam tajuk tanaman dapat dilihat dari nilai koefisien pemadaman yang besarnya tergantung dari struktur kanopi dan penyebaran daun di dalam kanopi.

Pertambahan bobot kering selama pertumbuhan dan perkembangan tanaman berbanding lurus dengan jumlah radiasi yang diintersepsi oleh tanaman, dimana produksi bahan kering terbesar pada suatu tanaman dicapai pada saat indeks luas daun mencapai 4.0 (Campbell, 1977). Menurut Handoko (1987), rata-rata efisiensi penggunaan radiasi merupakan gradien dari hubungan antara pertambahan bobot kering tanaman dengan kumulatif intersepsi radiasi.

Jika tidak terjadi kekurangan air dan zat hara, maka efisiensi penggunaan radiasi oleh tajuk tanaman ditentukan oleh intersepsi cahaya dan pola penyebaran di dalam tajuk tanaman (Newton dan Blackman, 1969). Untuk tanaman pertanian diperkirakan efisiensinya berkisar antara 4-20\% (Las, 1982). Sitaniapessy (1985) menyatakan bahwa penentuan efisiensi penggunaan radiasi dalam persen dapat diperoleh dengan mengkonversikan $1 \mathrm{~g}$ bobot kering $=17.5 \mathrm{~kJ}$ energi surya yang terpakai.

Menurut Las (1982), bila intensitas radiasi yang digunakan tanaman rendah, maka efisiensinya tinggi, karena semua energi akan digunakan. Sebaliknya tanaman yang menggunakan intensitas radiasi tinggi, maka efisiensi penggunaan radiasinya akan rendah. Setiap daun mempunyai tingkat efisiensi yang berbeda. Monteith (1977) menyatakan bahwa faktor tanaman yang berpengaruh terhadap efisiensi penggunaan radiasi adalah posisi dan sudut daun, struktur dan jenis pigmen.

Pada penelitian ini untuk mengetahui pertumbuhan (biomasa) tiga tanaman kedelai varietas Baluran, Bromo, dan Galunggung yang ditanam pada jarak tanam $15 \times 15 \mathrm{~cm}$ dan $25 \times 25 \mathrm{~cm}$ kaitannya dengan distribusi radiasi surya pada kanopi.

\section{Metode Penelitian}

Penelitian eksperimentasi ini dilaksanakan di sawah, dan analisis laboratorium dilakukan di Laboratorium Jurusan Pendidikan Biologi, FMIPA UNY. Alat dan bahan yang digunakan pada penelitian ini adalah box Solarimeter, timbangan mikro, oven, dan alat tanam. Bahan yang digunakan adalah biji kedelai varietas Baluran, Bromo, dan Galunggung, pupuk NPK, air, insektisida (Azodrin).

Penelitian ini menggunakan Rancangan Kelompok dengan tiga varietas kedelai dan dua jarak tanam yaitu $15 \times 15 \mathrm{~cm}$ dan $25 \times 25 \mathrm{~cm}$ dengan 10 ulangan. Parameter yang diamati intensitas cahaya dan biomasa tanaman kedelai. Data dianalisis menggunakan analisis ragam (Gomez dan Gomez, 1995).

Pelaksanaan penelitian mula-mula tanah sawah yang akan digunakan untuk penelitian diolah dan dibuat petak-petak dengan ukuran $2 \times 3 \mathrm{~m}$, dan setiap perlakuan jarak tanam terdiri atas tiga petak. Tanah sebelum ditanam kedelai dipupuk dengan NPK terlebih dahulu. Setiap lubang tugal ditanam tanaman kedelai. Pengamatan terhadap pengukuran transmisi cahaya dilakukan pada umur 20, 30, dan 40 hari setelah tanam (HST), dan sekaligus dilakukan pengkuran parameter bobot kering tanaman kedelai. Analisis data menggunakan analisis ragam (Gomez dan Gomez, 1995) untuk mengetahui apakah ada perbedaan respon pertumbuhan (biomasa) akibat jarak tanam berbeda pada ke tiga varietas kedelai. Untuk melihat apakah ada perbedaan antar perlakukan digunakan uji jarak Duncan (DMRT). 


\section{Hasil dan Pembahasan}

\section{Hasil Penelitian}

Hasil penelitian menunjukkan bahwa pada umur 20, 30 HST, intensitas cahaya matahari yang terdistribusi di dalam kanopi tanaman kedelai, faktor varietas menunjukkan perbedaan yang tidak nyata ( $\mathrm{p}>0.05)$, namun pada umur 40 HST berbeda nyata $(\mathrm{p}<0.05)$. Faktor jarak tanam hasil pengukuran intensitas pada ketiga umur pengamatan tersebut menunjukkan perbedaan yang nyata $(\mathrm{p}<0.05)$. Faktor interaksi varietas dan jarak tanam ke tiga umur pengamatan juga tidak nyata $(\mathrm{p}>0.05)$.

Hasil pengukuran intensitas cahaya yang terdistribusi lewat kanopi pada tiga tanaman kedelai varietas Baluran, Bromo, dan Galunggung pada umur 20, 30, dan 40 HST dengan tanpa memperhatikan faktor jarak tanam, disajikan pada Gambar 1 .

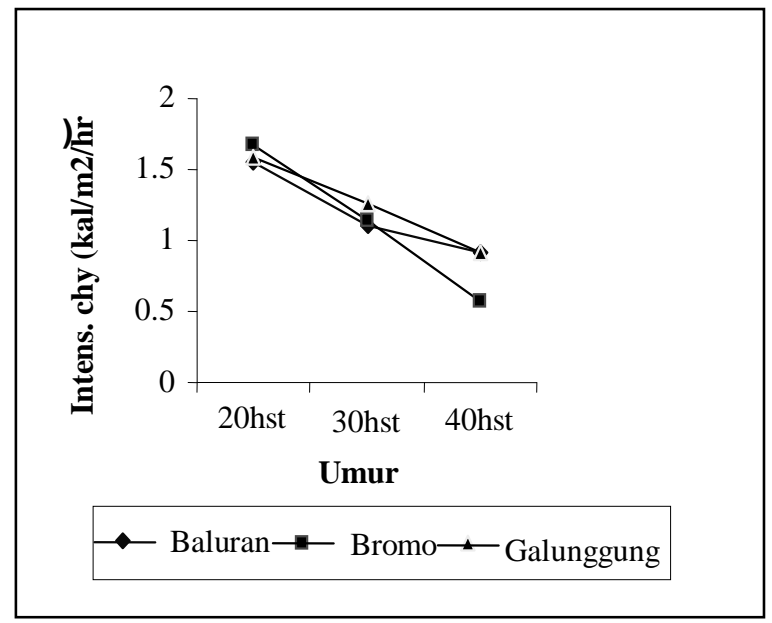

Gambar 1. Intensitas cahaya matahari pada tanaman kedelai umur 20, 30, dan 40 HST

Hasil penelitian menunjukkan bahwa biomasa tanaman kedelai pada umur 20, 30, dan 40 HST, faktor varietas menunjukkan perbedaan yang nyata $(\mathrm{p}<0.05)$, namun pada faktor jarak tanam hasil pengukuran biomasa pada ketiga umur pengamatan tersebut menunjukkan perbedaan yang tidak nyata ( $p>0.05)$. Pengaruh interaksi antara varietas dan jarak tanam terhadap biomasa untuk ke tiga umur pengamatan juga tidak nyata ( $>00.05)$. Hasil pengukuran biomasa pada varietas Baluran, Bromo, dan Galunggung pada umur 20, 30, dan 40 HST (dengan tanpa memperhatikan jarak tanam) disajikan pada Gambar 2.

Hasil pengukuran intensitas cahaya matahari tanaman kedelai varietas Baluran, Bromo, dan Galunggung pada jarak tanam $25 \times 25 \mathrm{~cm}$ dan $15 \times 15 \mathrm{~cm}$ umur 40 HST disajikan pada Gambar 3. Hasil pengukuran biomasa tanaman kedelai varietas Baluran, 178
Bromo, dan Galungung pada jarak tanam $15 \times 15 \mathrm{~cm}$ dan $25 \times 25 \mathrm{~cm}$ umur 40 HST disajikan pada Gambar 4.

Hasil pengukuran intensitas cahaya matahari dan biomasa varietas Baluran pada umur 40 HST disajikan pada Gambar 5a dan 5b. Hasil pengukuran intensitas cahaya matahari dan biomasa varietas Bromo pada umur 40 HST disajikan pada Gambar 6a dan 6b. Hasil pengukuran intensitas cahaya matahari dan biomasa varietas Galunggung pada umur 40 HST disajikan pada Gambar 7a dan $7 b$.

\section{Pembahasan}

Hasil pengukuran intensitas cahaya dari ke tiga pengamatan yang semakin bertambah umurnya, terjadi penurunan intensitas cahaya yang terdistribusi melewati kanopi tanaman kedelai (Gambar 1). Hal ini artinya bahwa Biota Vol. X (3), Oktober 2005 
semakin tambah umur tanaman kanopinya semakin lebat, sehingga tingkat naungannya semakin besar. Apabila dihubungkan dengan hasil pengamatan biomasanya, hasil penelitian menunjukkan bahwa semakin kecil intensitas cahaya yang melewati kanopi biomasanya semakin besar. Selama terjadi penyebaran intensitas cahaya matahari dalam kanopi, juga terjadi absorbsi intensitas cahaya oleh tanaman.

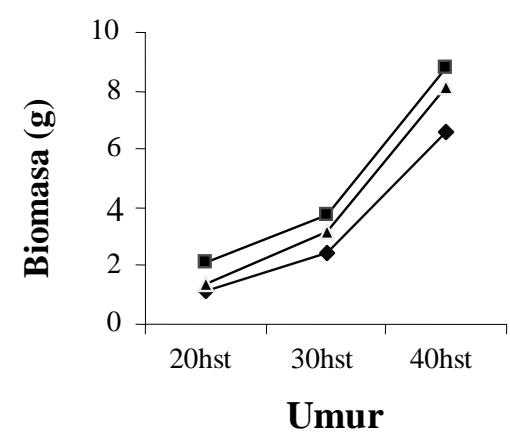

$\multimap$ Baluran $\rightarrow-$ Bromo $\longrightarrow$ Galunggung

Gambar 2. Biomasa tanaman kedelai umur 20, 30, dan 40 HST

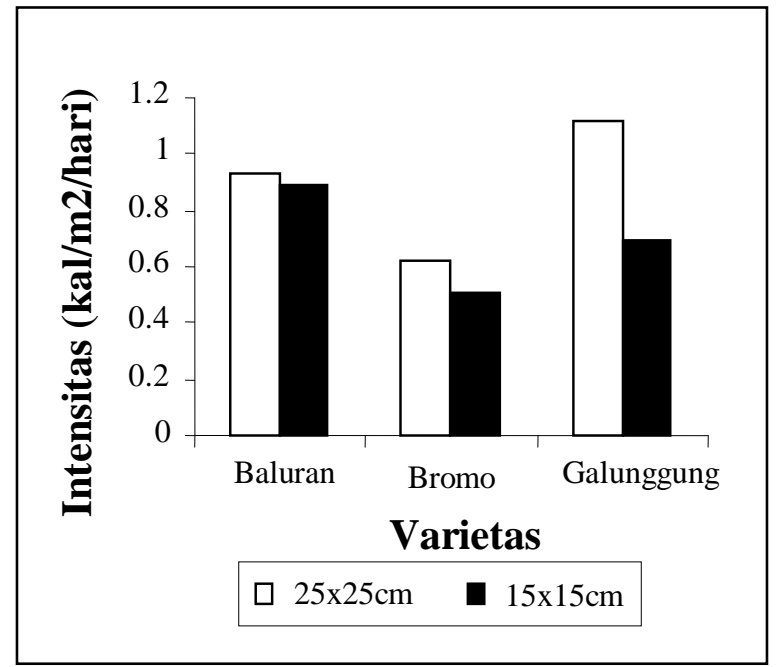

Gambar 3. Intensitas cahaya varietas Baluran, Bromo, dan Galunggung pada jarak tanam $25 \times 25 \mathrm{~cm}$ dan $15 \times 15 \mathrm{~cm}$

Absorbsi energi cahaya matahari oleh tanaman tersebut akan dimanfaatkan untuk pembentukan fotosintat yang disimpan dalam berbagai organ. Indikator tersimpannya fotosintat tersebut dapat ditunjukkan pada bobot kering tanaman atau biomasa (Gambar 2). Ritchie (1983) menyatakan bahwa hubungan antara radiasi cahaya yang diterima tanaman dengan laju pertumbuhan yang ditentukan oleh proporsi radiasi yang diserap dan efisiensi penggunaannya.

Pada umur 40 HST masing-masing varietas Baluran, Bromo, dan Galunggung, untuk jarak tanam $25 \times 25 \mathrm{~cm}$ intensitas cahaya yang melewati kanopi lebih tinggi bila dibandingkan dengan jarak tanam $15 \times 15 \mathrm{~cm}$ 
(Gambar 3), namun hasil pengukuran biomasa jarak tanam $25 \times 25 \mathrm{~cm}$ lebih kecil dibandingkan dengan jarak tanam 15x15 cm (Gambar 4). Bila ditinjau dari kerapatan tanaman, memang pada jarak tanam 25x25 cm lebih jarang jarak antar individu bila dibanding dengan jarak tanam $15 \times 15 \mathrm{~cm}$, sehingga intensitas yang terukur lebih tinggi. Hal ini sesuai dengan Loomis et al., (1968) yang menyatakan bahwa transmisi radiasi merupakan penerusan radiasi surya yang datang melalui sela-sela bagian tanaman dan mencapai bagian tertentu pada tanaman dipengaruhi oleh kerapatan tanaman.

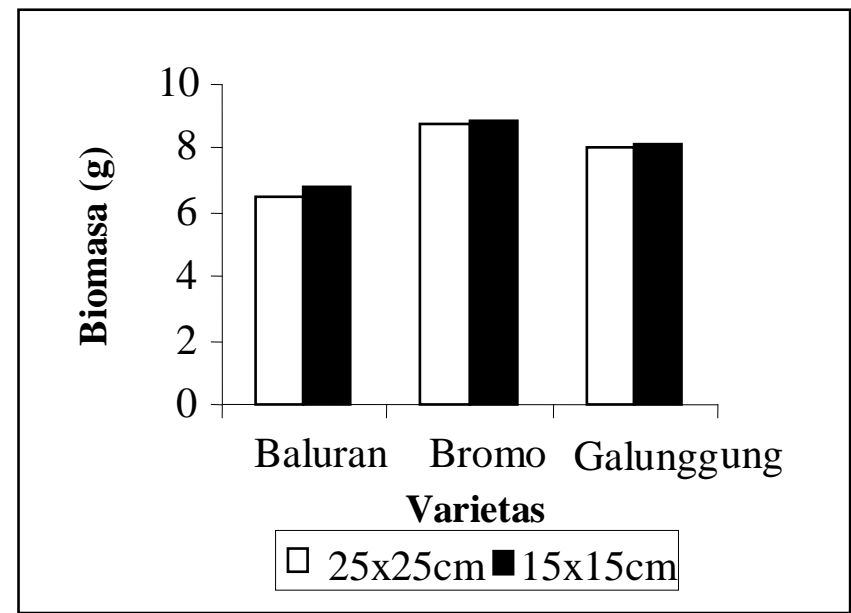

Gambar 4. Biomasa varietas Baluran, Bromo, dan Galunggung pada jarak tanam $25 \times 25 \mathrm{~cm}$ dan $15 \times 15 \mathrm{~cm}$
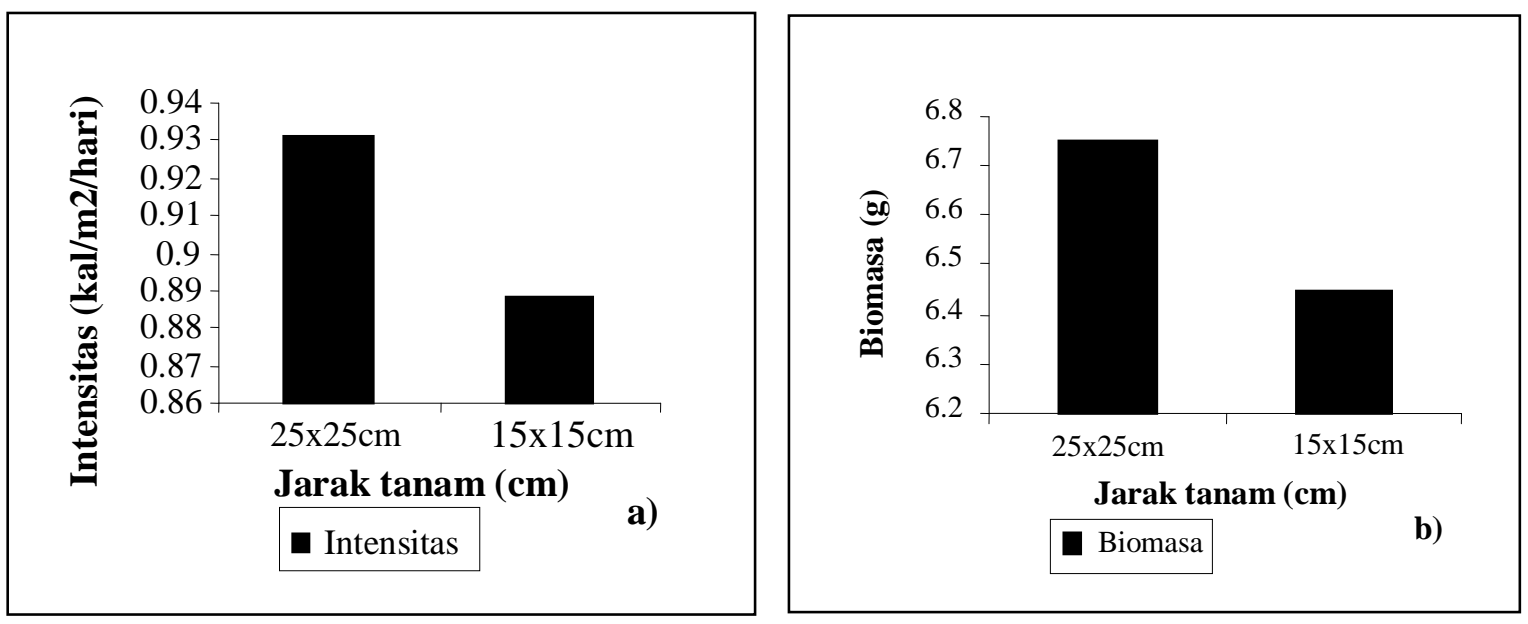

Gambar 5. Intensitas cahaya matahari (a) dan biomasa (b) varietas Baluran pada umur 40 HST

Tetapi bila ditinjau dari pengukuran bobot kering tanaman (biomasa), secara berturut-turut varietas Baluran, Bromo, dan Galunggung pada jarak tanam $15 \times 15 \mathrm{~cm}(6,754$ ; 8,840;8,141 g) lebih tinggi dibanding dengan $15 \times 15 \mathrm{~cm}(6,449 ; 8,728 ; 8,049 \mathrm{~g})$, walaupun secara tidak nyata $(p>0.05)$. Hal ini menunjukkan bahwa jarak tanam $15 \times 15 \mathrm{~cm}$ masih bisa disarankan, karena dengan biomasa yang tinggi diharapkan akan menghasilkan produksi kedelai yang tinggi pula. Shibles dan Weber (1965) menyatakan bahwa pada tanaman kedelai terdapat hubungan linier antara radiasi yang diintersepsi dengan laju pertumbuhan tanaman. Bobot kering akhir tanaman tergantung pada jumlah radiasi yang 
diintersepsi selama masa pertumbuhannya dan kerapatan tanaman.

Bila ditinjau dari masing-masing tiga varietas dan dibandingkan antar ke dua jarak tanam (Gambar 5a dan 5b ; 6a dan 6b ; 7a dan $7 b$ ), hasil pengukuran intensitas cahaya yang melewati kanopi yang tinggi menghasilkan biomasa tinggi pula. Hal ini menunjukkan bahwa pemanfaatan energi radiasi cahaya matahari untuk menghasilkan fotosintat mampu diakumulasikan di dalam tubuh tanaman. Menurut Sitaniapessy (1985), intersepsi radiasi surya oleh tanaman sebagian energi radiasi surya yang diserap dimanfatkan untuk pertumbuhan, sehingga laju pertumbuhan tanaman ditentukan oleh proporsi radiasi yang diserap dan efisiensi penggunaannya.
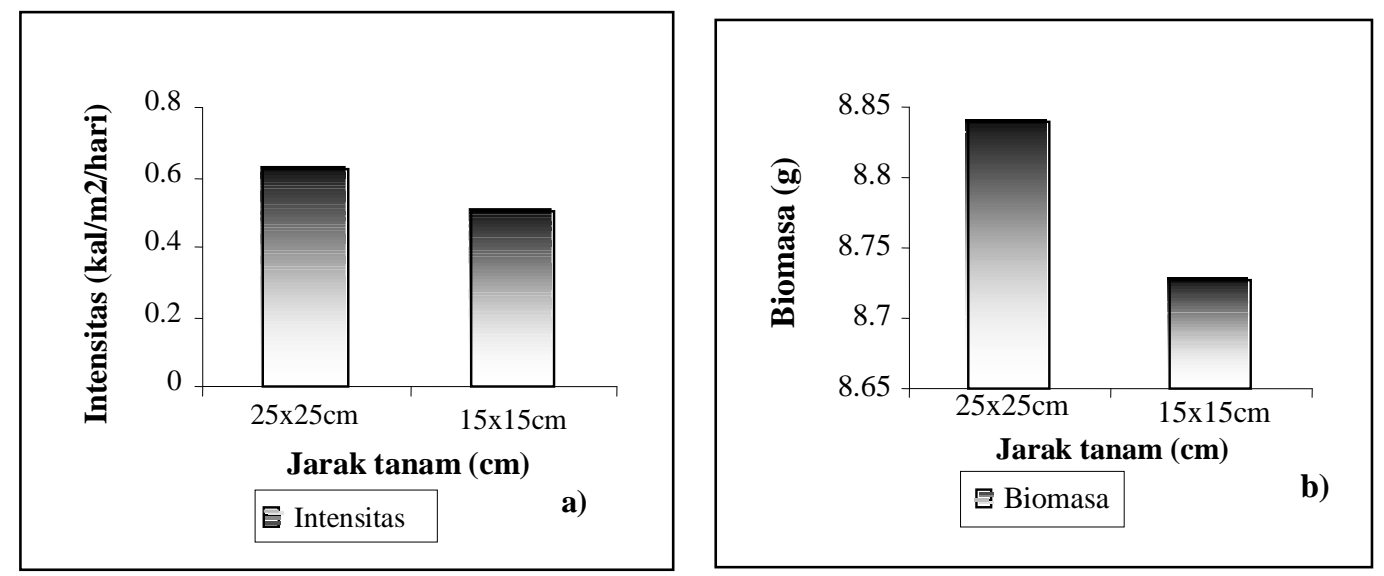

Gambar 6. Intensitas cahaya matahari (a) dan biomasa (b) varietas Bromo pada 40 HST
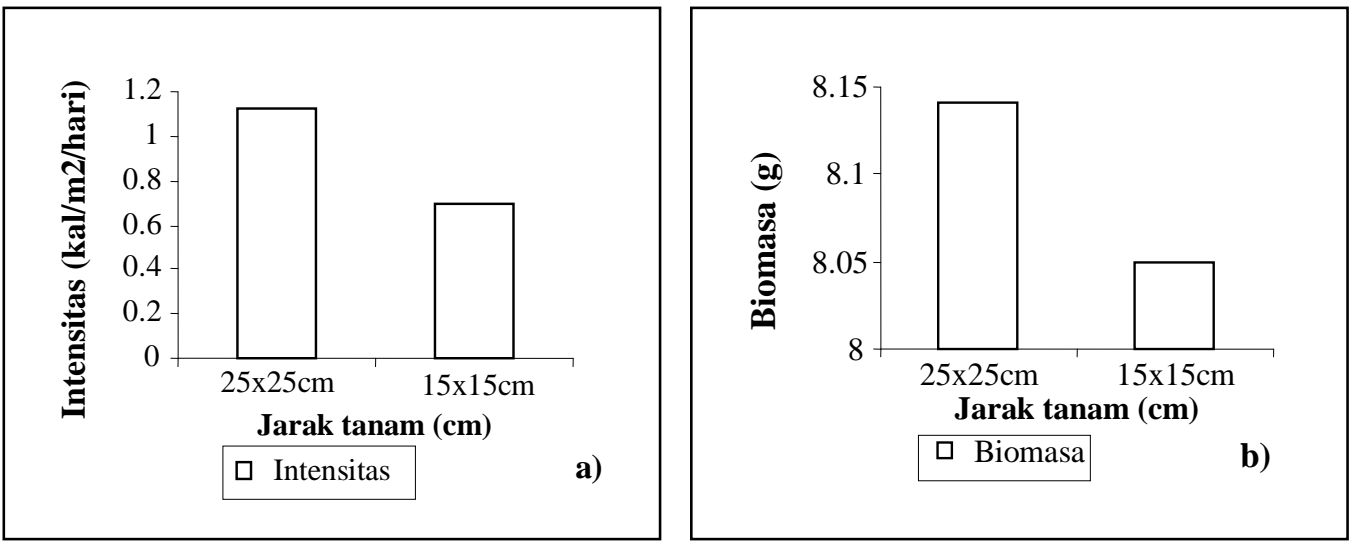

Gambar 7. Intensitas cahaya matahari (a) dan biomasa (b) varietas Galunggung pada umur 40 HST

\section{Kesimpulan}

1. Pada umur yang semakin meningkat, distribusi radiasi cahaya matahari melalui kanopi untuk ke tiga varietas kedelai semakin menurun, dan selanjutnya diikuti peningkatan biomasa.

2. Pada ke tiga varietas kedelai dengan jarak tanam yang lebih lebar (kepadatan tanaman lebih rendah), intensitas yang terukur lebih tinggi dibanding dengan tanaman yang kepadatannya tinggi.

3. Biomasa ke tiga varietas antar jarak tanam yang berbeda relatif sama (tidak berbeda nyata). 


\section{Daftar Pustaka}

Campbell, G.S. 1977. An Introduction to Environmental Biophisics. New York: Spring Verlag.

Gomez, K.A. dan Gomez, A.A. 1995. Prosedur Statistik untuk Penelitian Pertanian. Edisi II. (Diterjemahkan oleh Endang Sjamsudin dan Yustika S Baharsjah). Jakarta: Universitas Indonesia Press.

Handoko. 1987. Pendugaan Hasil dengan Menggunakan Indeks Iklim. Dalam Training Dosen PTN Indonesia Bagian Barat, Bidang Agroklimatologi. Bogor: IPB.

Janick, J. 1963. Horticulture Science. San Fransisco: W.H Freeman and Company.

Las, I. 1982. Agrometrologi dalam Budidaya Tanaman Pangan. Jurusan Geofisika dan Meteorologi. Bogor: FMIPA-IPB.

Loomis, R.S., William, W.A., Duncan, W.G., Dornat, A. and Nunez, F. 1968. Quantitative Description of Foliage Display and Light Absorbtion in Field Communities of Corn Plants. Crop. Sci. $8: 352-356$.

Monteith, J.L. 1977. Climate. In Alvin Paulo de T. and T.T Kozlowski (ed). Ecophysiology of Tropical Crops. New York: Academic Press.
Muchow, R.C., Coates, D.B., Wilson, G.L. and Foale, M.A. 1982. Growth and Productivity of Irrigated Sorghum bicolor (L.Moench) In.Northern Australia. I. Plant Density and Arrangement Effects on Light Interception and Distribution, and Grain Yield, in the Hybrid Texas 610 SR in Low and Medium Latitudes. Aust. J. Agric. Res. 33 : 773-784.

Newton, J.E. and Blackman, G.E. 1969. The Penetration of Solar Radiation Through Leaf Canopies of Different Structure. New York: Academic Press.

Ritchie, J.T. 1971. Dryland Evaporative Flux in Subhumid Climate. Micrometeorological Influences. Agron. J. 63 : 51-55.

Shibles, R.M. and Weber, C.R. 1965. Leaf Area, Solar Radiation Interception and Dry Matter Production by Soybean. Crop. Sci. 5 : 575577.

Sitaniapessy, P.M. 1985. Pengaruh Jarak Tanam dan Besarnya Populasi Tanaman terhadap Absorbsi Radiasi Surya dan Produksi Tanaman Jagung. Bogor: IPB.

Taiz, L. and Zeiger, E. 1991. Plant Physiology. Tokyo. The Benyamin/Cumming Publishing Company Inc. 